\title{
Effects of a Pharmacy-Driven Perisplenectomy Vaccination Program on Vaccination Rates and Adherence to Guidelines
}

\author{
Vanessa Meier-Stephenson, Shelly McNeil, Andrea Kew, Jennifer Sweetapple, Kara Thompson, \\ and Kathryn Slayter
}

\begin{abstract}
Background: Overwhelming postsplenectomy infection is a serious potential outcome for patients who have undergone resection of the spleen and is associated with a high mortality rate. The most common bacterial causes are the encapsulated organisms Streptococcus pneumoniae, Neisseria meningitidis, and Hemophilus influenzae type B, all of which are vaccine-preventable. Current guidelines recommend vaccination against these 3 bacteria, but adherence to these guidelines is less than ideal. In 2007, a "perisplenectomy vaccination kit" was introduced at the authors' institution to improve compliance with immunization guidelines by making the vaccines and necessary information for patients and providers more readily available.
\end{abstract}

Objective: To evaluate and compare vaccination rates for patients who underwent splenectomy before and after introduction of the perisplenectomy vaccination kit and, secondarily, to identify any characteristics unique to those who did not receive appropriate perisplenectomy vaccinations.

Methods: In this observational study, performed at the QEII Health Sciences Centre of Capital Health in Halifax, Nova Scotia, data were reviewed for patients who underwent splenectomy between 2008 and 2011. Vaccination rates and other descriptive statistics were calculated and compared with data for a 3-year period before implementation of the program.

Results: Vaccination rates in the 3-year period following implementation of the perisplenectomy vaccination kit were $100 \%$ against $S$. pneumoniae, $97 \%$ against $N$. meningitidis, and $93 \%$ against $H$. influenzae type B. The corresponding rates in the 3 years before introduction of the kit were $91 \%$, $75 \%$, and $68 \%$, respectively. No characteristics predicting inadequate immunization were identified in univariate or multivariate analysis.

Conclusion: Introduction of a pharmacy-driven perisplenectomy vaccination kit program improved rates of appropriate vaccination for patients who underwent splenectomy.

Keywords: splenectomy, vaccination, immunization, overwhelming postsplenectomy infection

\begin{abstract}
RÉSUMÉ
Contexte : L'infection fulminante post-splénectomie, une complication potentielle sérieuse chez les patients ayant subi une ablation de la rate, présente un taux de mortalité élevé. Les causes bactériennes les plus fréquentes de cette infection sont les bactéries encapsulées Streptococcus pneumoniae, Neisseria meningitidis et Haemophilus influenzae de type b, qui peuvent toutes être prévenues par un vaccin. Les lignes directrices actuelles recommandent une vaccination contre ces trois espèces de bactéries, mais le respect de ces lignes directrices est loin d'être idéal. En 2007, une " trousse de vaccination périsplénectomie " a été adoptée dans l'établissement des auteurs. Cette trousse avait pour but d'améliorer le degré de conformité aux lignes directrices sur l'immunisation en facilitant l'accès aux vaccins et aux renseignements nécessaires pour les patients et les professionnels de la santé.
\end{abstract}

Objectif : Déterminer quels étaient les taux de vaccination des patients ayant subi une splénectomie avant et après la mise en place de la " trousse de vaccination périsplénectomie ", puis comparer ces valeurs; et identifier toute caractéristique propre à ceux qui n’ont pas reçu les vaccins nécessaires durant la période entourant la splénectomie.

Méthodes : Dans cette étude observationnelle menée au QEII Health Sciences Centre de Capital Health à Halifax (Nouvelle-Écosse), on a procédé à l'analyse des données concernant les patients ayant subi une splénectomie entre 2008 et 2011. Les taux de vaccination ainsi que d'autres statistiques descriptives ont été calculés et comparés à des données d'une période de trois ans avant la mise en œuvre du programme d'utilisation de la «trousse de vaccination périsplénectomie ".

Résultats : Les taux de vaccination de la période de trois ans qui a suivi la mise en œuvre de la « trousse de vaccination périsplénectomie » étaient de $100 \%$ pour $S$. pneumoniae, $97 \%$ pour $N$. meningitidis et $93 \%$ pour $H$. influenzae de type b. Les taux correspondants des trois années précédant cette mise en œuvre étaient respectivement de $91 \%$, $75 \%$ et $68 \%$. Aucun prédicteur d'une immunisation insuffisante n'a été cerné par l'analyse univariée ou multivariée.

Conclusion : L'implantation d'un programme de « trousse de vaccination périsplénectomie " mené par les pharmaciens a permis d'accroître les taux d'administration des vaccins qui sont indiqués chez les patients ayant subi une splénectomie.

Mots clés : splénectomie, vaccination, immunisation, infection fulminante post-splénectomie

[Traduction par l'éditeur] 


\section{INTRODUCTION}

$\mathrm{P}$ atients who have had their spleen removed are at high risk of overwhelming postsplenectomy infection, which is associated with a high mortality rate. ${ }^{1,2}$ The most common bacterial causes for this complication are the encapsulated organisms Streptococcus pneumoniae, Neisseria meningitidis, and Hemophilus influenzae type $\mathrm{B}$, all of which are vaccinepreventable. ${ }^{1,2}$ Immunization guidelines recommend vaccination for each of these organisms to prevent infection in this high-risk population. At the time of implementation of the study program, the recommended vaccines, according to the 2006 Canadian Immunization Guide, were 23-valent pneumococcal polysaccharide vaccine (PPV-23), meningococcal $\mathrm{C}$ conjugate vaccine, and $H$. influenzae vaccine. ${ }^{3,4}$ The recommended timing of vaccination was either 2 weeks before splenectomy (in the case of elective procedures) or 2 weeks postoperatively, to allow for appropriate immune response. ${ }^{3,4}$ Yearly influenza vaccination was also recommended. ${ }^{3,4}$

Adherence to the recommended vaccination guidelines is less than ideal at many hospitals, ${ }^{5-9}$ and the authors' institution was no exception. Between 2002 and 2004, a total of 70 patients underwent splenectomy at this facility; of these, vaccination status was recorded for 65, of whom 59 (91\%) received vaccination against $S$. pneumonia, 49 (75\%) against $N$. meningitides, and $44(68 \%)$ against $H$. influenzae. ${ }^{5}$

Recognizing the need to improve vaccination rates, a "perisplenectomy vaccination kit" program was introduced in 2007, to aid in implementation of current recommendations for perisplenectomy vaccination. The kit, which is still in use, consists of a standing order for perisplenectomy vaccinations, a patient information sheet describing overwhelming postsplenectomy infection, a standardized follow-up letter for the family physician, the 3 recommended vaccines, and a patient wallet card documenting vaccinations received.

A focus group involving pharmacists (both staff and pharmacy managers), nurse managers from general surgery, and nursing educators was convened to determine the best way to stock and disseminate the kits. It was decided that the kits would be assembled and kept in the pharmacy. When a patient was to undergo splenectomy, a sticker or chart flag would be placed on the chart by any member of the team to remind clinical staff to order a perisplenectomy vaccination kit, a physician would sign the standing order included in the kit, and a certified nurse would administer the vaccines. Information about the program was brought to the Nurse Educator Council, so that nurse educators could pass the information on to their respective areas. An information session was held during Surgery Grand Rounds to remind house staff of the infection risks for patients who have undergone splenectomy and to inform them of the program.

Four years after implementation of the perisplenectomy vaccination kit program, the current study was undertaken to determine vaccination rates for this at-risk population and, secondarily, to determine whether any factors were associated with failure to receive the appropriate vaccinations.

\section{METHODS}

This observational study, conducted at the QEII Health Sciences Centre of Capital Health in Halifax, Nova Scotia, examined data for the 3-year period from 2008 to 2011, i.e., since implementation of the perisplenectomy vaccination program. The study was approved by the Capital Health Research Ethics Board. Patients were identified through a review of the Operating Room Information System using the surgical code for splenectomy. All patients who underwent splenectomy between 2008 and 2011 were eligible for inclusion. Exclusion criteria were death during or within 2 weeks after the operation and incomplete vaccination data; only the absence of information about receipt of a vaccine (not absence of information about the timing of vaccination) was deemed to constitute incomplete data.

Medical records were reviewed by one of the authors (V.M.-S.), who collected the following information (recorded in a Microsoft Access database): age and sex; indication for splenectomy; receipt, timing, and documentation of vaccinations; and documentation in the surgical discharge summary, including report of splenectomy, documentation of vaccines administered, recommendations for future vaccines, recommendations for a MedicAlert bracelet, and counselling about the risk of overwhelming postsplenectomy infection.

For patients whose medical record lacked in-hospital documentation of vaccinations or other recommendations and who were determined to still be alive, a letter was sent to the patient's family physician requesting details about the administration of vaccines outside the hospital. If no response was received after 6 weeks, a second letter was mailed. If it was determined that a patient had not received all of the recommended vaccinations, an additional letter was sent to the family physician providing guidance on required vaccines, so that the physician could arrange for vaccine administration according to guidelines current at the time of the study. ${ }^{3}$

Vaccination rates for each of the recommended vaccines were determined to allow comparison with historical controls (before implementation of the perisplenectomy vaccination program) reviewed in the previous study. ${ }^{5}$ Although immunization guidelines had been updated in the interval between the 2 cohorts, the recommendations were similar enough to allow direct comparisons of rates. ${ }^{3,10}$ Descriptive statistics were tabulated to summarize the demographic characteristics of the current study population. Discrete variables were summarized with frequency counts, percentages, and confidence intervals, and data were compared using the Fisher exact test, global Wald $\chi^{2}$ test, and paired $t$ tests. Characteristics of patients who received all appropriate vaccinations (regardless of timing) were compared 


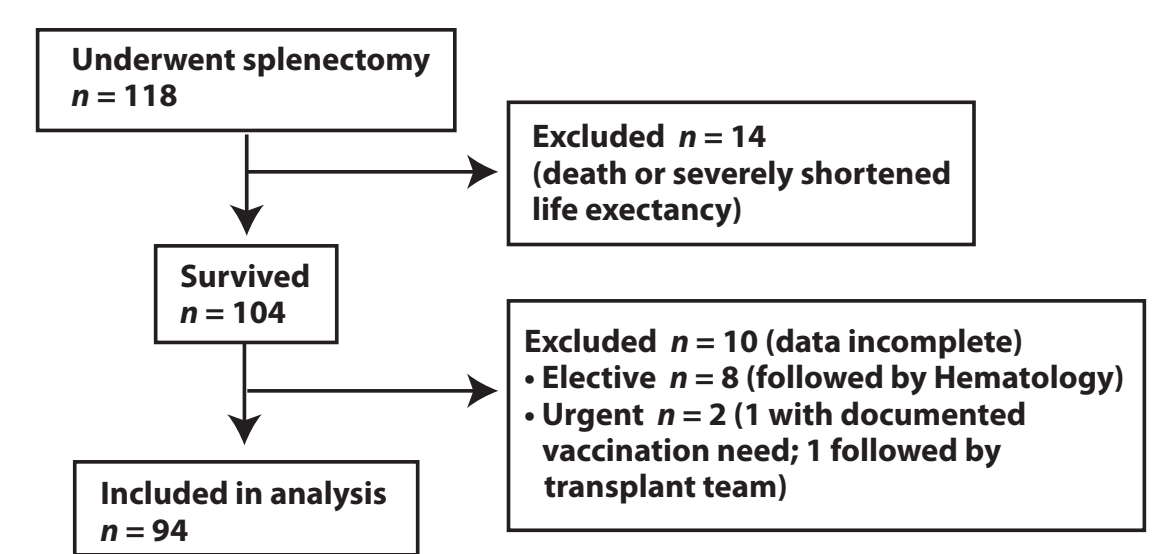

Figure 1. Patients included in the study.

with characteristics of patients whose vaccination status was found to be deficient, to determine if any factors could be associated with incomplete immunization.

SAS statistical software, version 9.2 (SAS Institute Inc., Cary, North Carolina) was used to analyze the results.

\section{RESULTS}

Medical records were reviewed for a total of 118 patients who underwent splenectomy during the 3-year study period. Of these, 94 met the inclusion criteria and were included in the analysis (Figure 1). Fourteen of the patients were excluded because they died either during or within 2 weeks after the surgery. Another 10 were excluded because vaccination data were incomplete. Of those 10 patients, 8 were followed by the hematology service, and all had documentation in clinic notes that recommendations about vaccination had been conveyed to the family physician. The remaining 2 cases involved urgent surgery. For one of the patients, documentation of both the procedure and vaccination requirements was present in the discharge summary, whereas the other patient had documentation of neither. For the latter patient, who was a solid-organ transplant recipient, documentation of the splenectomy was lacking in the operative report, ward progress notes, and follow-up clinic letters; the procedure was confirmed by review of the pathology report.

Of the 104 cases in which the patients survived at least 2 weeks after surgery, 29 (28\%) required contact with the family physician to request clarification, if possible, of patients' vaccination deficiencies. The overall response rate from family physicians was $79 \%$ (23/29).

Overall vaccination rates were calculated for each recommended vaccine and compared with the rates observed in the study institution for a 3-year period before implementation of the perisplenectomy vaccination kit (Table 1). Statistically significant increases in immunization rates for all 3 of the recommended vaccines were observed following implementation of the program, with absolute rate increases of 9,22 , and 25 percentage points for pneumococcal, meningococcal, and $H$. influenzae type B vaccines, respectively.

The majority of patients who underwent splenectomy were male (Table 2), and the overall mean age was 55 years. The most common indications for splenectomy were unintentional splenic injury during abdominal surgery and idiopathic thrombocytopenic purpura or autoimmune hemolytic anemia (Table 2). The rate of nonelective surgery was higher among patients in the current study than among historical controls (43/94 [46\%] versus $13 / 65$ [20\%]). Overall, vaccines were administered at an appropriate interval before or after splenectomy for 61 (65\%) of the 94 patients. Although some differences were observed between patients with and without appropriate vaccination, no statistically significant differences predicting inadequate immunization were identified in univariate or multivariate analysis.

Information included in the discharge summaries sent to family physicians was evaluated to assess the adequacy of communication regarding performance of splenectomy, the related risk of infection, and prevention recommendations (Table 3). A statement that the patient had undergone splenectomy was documented in all but $2(2 \%)$ of the discharge summaries; 62 $(66 \%)$ of the discharge summaries documented which vaccines had been given in hospital, 17 (18\%) provided instructions about

\section{Table 1. Vaccination Rates Before and After} Perisplenectomy Vaccine Program

\begin{tabular}{lccccc}
\multirow{2}{*}{ Vaccine } & \multicolumn{2}{c}{ Timeframe; No. (\%) of Patients } & & p Value \\
\cline { 2 - 4 } & \multicolumn{2}{c}{$\begin{array}{l}\text { Before* } \\
(\boldsymbol{n}=\mathbf{6 5})\end{array}$} & $\begin{array}{c}\text { Aftert } \\
(\boldsymbol{n}=\mathbf{9 4})\end{array}$ & \\
\hline Pneumococcal & 59 & $(91)$ & 94 & $(100)$ & 0.004 \\
\hline Meningococcal & 49 & $(75)$ & 91 & $(97)$ & $<0.001$ \\
\hline Hemophilus & 44 & $(68)$ & 87 & $(93)$ & $<0.001$ \\
\hline Data &
\end{tabular}

Data from 2002-2004, published previously. ${ }^{5}$

tData from 2008-2011 (current study). 
This single copy is for your personal, non-commercial use only.

For permission to reprint multiple copies or to order presentation-ready copies for distribution, contact CJHP at cjhpedit@cshp.ca

Table 2. Demographic and Surgical Characteristics of Patients

\begin{tabular}{|c|c|c|c|c|c|c|c|}
\hline \multirow{2}{*}{$\begin{array}{l}\text { Characteristic } \\
\text { Sex }\end{array}$} & \multicolumn{6}{|c|}{ Vaccination Status; No. (\%) of Patients } & \multirow[b]{2}{*}{$p$ Value* } \\
\hline & \multicolumn{2}{|c|}{$\begin{array}{l}\text { Fully Vaccinated } \\
\qquad(n=84)\end{array}$} & \multicolumn{2}{|c|}{$\begin{array}{l}\text { Not Fully } \\
\text { Vaccinated } \\
(n=10)\end{array}$} & \multicolumn{2}{|c|}{$\begin{array}{c}\text { Total } \\
(n=94)\end{array}$} & \\
\hline Men & 52 & $(62)$ & 3 & (30) & 55 & (59) & \\
\hline Women & 32 & (38) & 7 & (70) & 39 & (41) & \\
\hline Age (years) & & & & & & & 0.10 \\
\hline$<30$ & 12 & (14) & 2 & (20) & 14 & (15) & \\
\hline $30-59$ & 34 & (40) & 1 & (10) & 35 & (37) & \\
\hline $60-80$ & 36 & (43) & 5 & (50) & 41 & (44) & \\
\hline$>80$ & 2 & (3) & 2 & $(20)$ & 4 & (4) & \\
\hline Indication & & & & & & & NA \\
\hline Trauma & 16 & (19) & 0 & $(0)$ & 16 & $(17$ & \\
\hline Abdominal surgery injury & 19 & (23) & 3 & (30) & 22 & (23) & \\
\hline Primary splenic disorder & 13 & (15) & 1 & (10) & 14 & (15) & \\
\hline ITP or AIHA & 21 & (25) & 4 & (40) & 25 & $(27)$ & \\
\hline Hematologic malignancy & 14 & (17) & 1 & (10) & 15 & (16) & \\
\hline Other malignancy & 1 & (1) & 1 & (10) & 2 & $(2)$ & \\
\hline Urgency & & & & & & & 0.75 \\
\hline Urgent & 37 & (44) & 6 & (60) & 43 & (46) & \\
\hline Elective & 47 & (56) & 4 & (40) & 51 & (5) & \\
\hline Timing of vaccination & & & & & & & $>0.99$ \\
\hline $\begin{array}{l}\text { Presplenectomy or } \\
\text { postsplenectomy }\end{array}$ & 54 & (64) & 7 & (70) & 61 & (65) & \\
\hline Perisplenectomy & 30 & (36) & 3 & (30) & 33 & (35) & \\
\hline
\end{tabular}

ITP = idiopathic thrombocytopenic purpura, AlHA = autoimmune hemolytic anemia.

*For comparison between patients who were fully vaccinated and those not fully vaccinated.

+Vaccine given $\geq 2$ weeks before splenectomy or $\geq 2$ weeks after splenectomy, as per guidelines.

$\neq$ ₹accine given within 2 weeks before or after splenectomy.

which vaccines the patient required after discharge, and 7 (7\%) provided general information about overwhelming postsplenectomy infection. Compared with the historical controls, documentation and/or recommendations for vaccination in the discharge summaries improved from $27 \%$ to $82 \%(p<0.001)$. No statistically significant differences were observed between fully vaccinated patients and those with inadequate vaccination to indicate a relationship between inclusion of key statements related to the patient undergoing splenectomy and whether the patient received appropriate vaccinations (Table 3).

Perisplenectomy vaccination kits were ordered for 44 (47\%) of the patients included in the analysis, $40(91 \%)$ of whom had undergone splenectomy on an urgent basis. Those who underwent urgent splenectomy derived the greatest benefit from use of the splenectomy kit: if a splenectomy kit was ordered, a patient was 4.6 times more likely to be fully vaccinated ( $95 \%$ confidence interval 0.78-27.25).

\section{DISCUSSION}

Vaccination rates between 2008 and 2011 were significantly higher than rates before introduction of the perisplenectomy vaccination kit program for each of the 3 recommended vaccines.
Thus, the results of the current study showed a measurable benefit of the introduction of a comprehensive perisplenectomy vaccination kit program to increase adherence to immunization guidelines. Although the kit provides a convenient way to prescribe and document receipt of vaccines for all patients undergoing splenectomy, it appeared to offer the greatest benefit for those undergoing urgent splenectomy. This is not a surprising result, as immunization planning, consultation, and preoperative vaccination can readily be organized for patients undergoing elective procedures but are often overlooked in the setting of urgent procedures, for which delay in vaccination until after discharge from hospital is frequently necessary. In this situation, a readily available, prepackaged kit covering all of the necessary instructions for vaccination offers clear benefit, and the odds of vaccination were almost 5 times higher for this group of patients when a splenectomy kit was used.

Identification of factors associated with inadequate vaccination in this high-risk population is important to inform strategies to optimize vaccine uptake. Although clinical, demographic, and surgical features of patients were examined to identify features potentially associated with inadequate vaccination, the relatively small sample size resulted in insufficient power to detect such differences. Future studies should be appropriately powered to 
This single copy is for your personal, non-commercial use only.

For permission to reprint multiple copies or to order presentation-ready copies for distribution, contact CJHP at cjhpedit@cshp.ca

Table 3. Discharge Documentation of Splenectomy, Related Risk of Infection, and Prevention Recommendations

\begin{tabular}{|c|c|c|c|c|c|c|c|}
\hline \multirow{3}{*}{$\begin{array}{l}\text { Element of } \\
\text { Documentation }\end{array}$} & \multicolumn{6}{|c|}{ Vaccination Status; No. (\%) of Patients } & \multirow[b]{2}{*}{$p$ Value* } \\
\hline & \multicolumn{2}{|c|}{$\begin{array}{l}\text { Fully Vaccinated } \\
\qquad(n=84)\end{array}$} & \multicolumn{2}{|c|}{$\begin{array}{l}\text { Not Fully } \\
\text { Vaccinated } \\
(n=94)\end{array}$} & \multicolumn{2}{|c|}{ Total } & \\
\hline & 82 & (98) & 10 & $(100)$ & 92 & (98) & $>0.99$ \\
\hline Vaccinations received & 58 & (69) & 4 & $(40)$ & 60 & $(66)$ & 0.08 \\
\hline $\begin{array}{l}\text { Vaccinations } \\
\text { recommended }\end{array}$ & 14 & $(17)$ & 3 & (30) & 17 & (18) & 0.38 \\
\hline $\begin{array}{l}\text { Information regarding } \\
\text { OPSI }\end{array}$ & 7 & (8) & 0 & (0) & 7 & (7) & $>0.99$ \\
\hline
\end{tabular}

assess predictors of inadequate immunization. In most cases, no clear reasons for inadequate vaccination were documented. The vaccine most likely to be overlooked was $H$. influenzae type B, perhaps because of the inappropriate assumption that the vaccine is unnecessary if the patient reports that he or she was fully vaccinated as a child. Awareness about the need for pneumococcal vaccination seemed high, with in-hospital receipt of vaccines, discharge recommendations, and postdischarge vaccination resulting in $100 \%$ of patients being fully immunized, but there remained room for improvement in the provision of both meningococcal and $H$. influenzae type $\mathrm{B}$ vaccines.

Although review of hospital discharge summaries provided some insight into the level of awareness about immunization among hospital-based clinicians, the presence or absence of documentation of immunization or immunization recommendations in the summaries did not always correlate with a patient's receipt of a vaccine. Documentation was generally poor, but significant improvements were achieved following implementation of the perisplenectomy vaccination kit. These improvements suggested that the kit addressed deficiencies in documentation by providing comprehensive, standardized, easy-to-use materials that facilitated transfer of information between healthcare providers and the patient.

Relative to the historical cohort, more of the splenectomies in the 2008-2011 cohort were nonelective. This difference may have been partially related to a greater number of abdominal surgeries being performed; however, further conclusions on this matter would be speculative.

In addition to its small sample size, the potential limitations of this study included its retrospective nature, although selection bias and confounders were controlled by appropriate design, data collection, and analysis. A further major limitation would be the lack of generalizability of this study to other institutions, for example, those with fully computer-based orders and records, those where the rate of splenectomy is much lower, or those with other unknown factors differing from the study institution. Such differences would ultimately modify the context of development and dissemination of a splenectomy kit, thus affecting the external validity of this study.
Canadian immunization guidelines are changing again. Recent Canadian guidelines have recommended that patients undergoing splenectomy receive 13-valent pneumococcal conjugate vaccine (PCV-13), followed by PPV-23 and a booster dose of PPV-23 after 5 years; 2 doses of quadrivalent conjugate meningococcal vaccine 8 weeks apart and booster doses every 5 years; and $H$. influenzae type $\mathrm{B}$ vaccine, even if the previous childhood series was completed. ${ }^{11,12}$

As immunization recommendations continue to evolve and perisplenectomy vaccination schedules become even more complex (as is the case with most recent vaccination recommendations), it will be increasingly difficult for the diverse array of clinicians caring for patients undergoing splenectomy to remain up to date. This situation will likely lead to poor adherence with guidelines, and a growing proportion of asplenic patients may be left with suboptimal protection against infection. Use of a standardized, comprehensive, pharmacy-driven perisplenectomy vaccination kit allows rapid translation of new recommendations to clinicians and provides ready access to newly recommended vaccines and supporting information.

\section{References}

1. Lynch AM, Kapila R. Overwhelming postsplenectomy infection. Infect Dis Clin North Am. 1996;10(4):693-707.

2. Lortan JE. Management of asplenic patients. Br J Hematol. 1993;84(4):566-9.

3. Public Health Agency of Canada, National Advisory Committee on Immunization. Immunization of immunocompromised persons. In: Canadian immunization guide. 7th ed. Ottawa (ON): Public Health Agency of Canada; 2006 [cited 2011 Jun 1]. p. 117-30. Available from: http:// publications.gc.ca/collections/Collection/HP40-3-2006E.pdf

4. National Advisory Committee on Immunization. Statement on conjugate meningococcal vaccine for serogroups A,C, Y and W135. Can Commun Dis Rep. 2007;33(CS-3):1-24. Also available from: www.phac-aspc.gc.ca/ publicat/ccdr-rmtc/07vol33/acs-03/

5. Kew A, White D, Slayter K. Survey of vaccine administration to splenectomized patients: Are guidelines being followed? Can J Infect Dis Med Microbiol. 2008;19(2):206.

6. Pickering J, Campbell H. An audit of the vaccination and antibiotic prophylaxis practices amongst patients splenectomised in Lothian. Health Bull (Edinb). 2000;59(5):390-5.

7. O’Donnell J, McGreal G, Daly P, Crowley R, Barry MC, Broe P, et al. Management of patients undergoing splenectomy in an Irish teaching hospital: impact of guidelines. Irish J Med Sci. 2004;173(3):136-40. 
This single copy is for your personal, non-commercial use only.

For permission to reprint multiple copies or to order presentation-ready copies for distribution, contact CJHP at cjhpedit@cshp.ca

8. Ramachandra J, Bond A, Ranaboldo C, Cullis J. An audit of postsplenectomy prophylaxis-Are we following the guidelines? Ann R Coll Surg Engl. 2003;85(4):252-5.

9. Lammers AJ, Veninga D, Lombarts MJ, Hoekstra JB, Speelman P. Management of post-splenectomy patients in the Netherlands. Eur J Clin Microbiol Infect Dis. 2010;29(4):399-405.

10. Health Canada, National Advisory Committee on Immunization. Canadian immunization guide. 6th ed. Ottawa (ON): Public Health Agency of Canada; 2002 [cited 2011 Jun 1]. Available from: http://publications. gc.ca/collections/Collection/H49-8-2002E.pdf. Chapters of interest: "Immunization in immunocompromised hosts" (p. 21-30), "Meningococcal vaccine" (p. 151-65), and "Pneumococcal vaccine" (p. 175-84).

11. National Advisory Committee on Immunization. Update on the use of quadrivalent conjugate meningococcal vaccines. Can Commun Dis Rep. 2013;39(ACS-1):1-40.

12. National Advisory Committee on Immunization (NACI). Statement on the use of conjugate pneumococcal vaccine -13 valent in adults (PneuC-13).Can Commun Dis Rep. 2013;39(ACS-5):1-52.

Vanessa Meier-Stephenson, MD, PhD, was, at the time of manuscript preparation, an Internal Medicine resident with the Faculty of Medicine, Dalhousie University, and the Department of Medicine, Capital Health, Halifax, Nova Scotia. She is currently completing an Infectious Diseases residency at the University of Calgary, Calgary, Alberta.

Shelly McNeil, MD, is with the Faculty of Medicine, Dalhousie University, and the Department of Medicine and Division of Infectious Diseases, Capital Health, Halifax, Nova Scotia.

Andrea Kew, MD, is with the Faculty of Medicine, Dalhousie University, and the Department of Medicine and Division of Hematology, Capital Health, Halifax, Nova Scotia.
Jennifer Sweetapple, MSc, is with the Department of Pharmacy, Capital Health, Halifax, Nova Scotia.

Kara Thompson, MSc, is with the Research Methods Unit, IWK Health Centre and Capital Health, Halifax, Nova Scotia.

Kathryn Slayter, PharmD, is with the Department of Medicine, the Division of Infectious Diseases, and the Department of Pharmacy, Capital Health, Halifax, Nova Scotia.

Competing interests: Kathryn Slayter has received research funds from Wyeth Ayerst (now Pfizer) and speakers' honoraria from Pfizer Canada. Shelly McNeil has received research funding from Pfizer Canada, GlaxoSmithKline, and Sanofi Pasteur and speakers' honoraria from Pfizer Canada. Andrea Kew has received consulting fees or honoraria from Novartis, Celgene, Jenssen, and Pfizer. No other competing interests declared.

\section{Address correspondence to:}

Dr Kathryn Slayter

Pharmacy

QEIl Health Sciences Centre

1276 South Park, Room 2-043 Victoria Building

Halifax NS B3H 2 Y9

e-mail: kathryn.slayter@cdha.nshealth.ca

\section{Acknowledgements}

This study was funded by peer-reviewed funding through the Capital Health Research Fund. The authors would like to acknowledge Chris Theriault, Database Consultant, Department of Medicine, Capital Health, for database development. 